\title{
Academic performance in Iranian medical students during the pre-clinical stage
}

\author{
Farnoush Davoudi ${ }^{1}$, Shooka Esmaeeli ${ }^{1}$, Masoud AhmadzadAsl ${ }^{2}$, Marzieh Nojomi ${ }^{1 *}$
}

\begin{abstract}
Background: Better understanding of factors associated with medical school performance is necessary to improve admission processes and to help students succeed in their career. This study follows a group of Iranian med students during their first 2.5 years of medical education, to evaluate their academic success in accordance with their demographic, cognitive and non-cognitive characteristics.

Methods: 143 of 200 matriculants of Iran University of Medical Sciences medical school in 2010, were followed for 5 consecutive semesters of the preclinical stage. Demographic and cognitive characteristics were collected using self-administered data collection forms. The NEO Five-Factor (personality) Inventory (NEO-FFI) was used to assess participants' non-cognitive characteristics. The 5 semesters' cumulative Grade Point Average (GPA) was the measure of academic performance. Pooled t-test, one-way ANOVA, multiple linear regression and logistic regression model, and Spearman coefficients of correlation were applied in data analysis

Results: There was a significant difference in participants' GPA regarding their gender $(\mathrm{p}=0.008)$, using privilege in National University Entrance Examination (NUEE) $(\mathrm{p}<0.0001)$, the number of times one has taken part in NUEE $(\mathrm{p}=0.034)$ and being occupied in paid jobs $(\mathrm{p}=0.01)$. There were no significant differences in participants' GPA regarding NEO-FFI domains.

Conclusions: Females and students with a better academic performance prior to their admission in medical school had better academic records. We found no association between academic performance and personality because participants were followed through a preclinical stage where non-cognitive characteristics plays a less important role in their performance and evaluations.
\end{abstract}

Keywords: Students, Medical education, Medicine, Undergraduate, Iran

Copyright $₫$ Iran University of Medical Sciences

Cite this article as: Davoudi F, Esmaeeli S, AhmadzadAsl M, Nojomi M. Academic performance in Iranian medical students during the pre-clinical stage. Med J Islam Repub Iran. 2017 (24 Feb);31:14. https://doi.org/10.18869/mjiri.31.14

\section{Introduction}

Medical carriers are noble since physicians are directly involved in the life of human beings. Therefore, medical schools try to select the most promising students who would perform well as undergraduate students and become good practitioners in the future (1).

Many studies have addressed predictors of medical students' academic success. These predictors are mainly categorized into three groups of "Demographic", "Cognitive" and "Non-cognitive" characteristics (2). Commonly addressed demographics are "gender"(3-7), "age"(3), "marital status"(8), "being occupied in paid jobs during education"(3) and "the high school one has attended" (1). The

Corresponding author: Dr Marzieh Nojomi, mnojomi@iums.ac.ir

1. Preventive Medicine and Public Health Research Center, Department of Community Medicine, Iran University of Medical Sciences, Tehran, Iran.

2. Mental Health Research Center, Department of Psychiatry, Iran University of Medical Sciences, Tehran, Iran. "academic performance" of students prior to their admission to medical school and "results of university entrance examinations" $(2,8-16)$ are common proxies for cognitive abilities. The non-cognitive personal qualities usually consist of "personality traits" and factors like "moral/ethical reasoning" $(1,5-7,10,12-24)$.

Iran has a direct undergraduate medical school admission system. Applicants should compete in National University Entrance Examination (NUEE). The NUEE is a highly competitive, cognitive ability testing, centralized and governmentally administered examination. It covers high school course topics (e.g. Biology, Math, etc.) and is be-

$\uparrow$ What is "already known" in this topic:

There are "Demographic", "Cognitive" and "Non-cognitive" predictors of medical students' academic success.

$\rightarrow$ What this article adds:

Gender, privilege in university admission and frequency of participation in national university entrance examination are predictors of Iranian medical students' academic success after 2.5 years of education. 
ing held once a year. The eligible NUEE candidates are high school graduates who have received High School Graduation Diploma (HSGD) and completed the one-year Pre-University Courses (PUC). The best-ranked candidates, according to NUEE scores, are admitted into the public medical schools.

Iran's 7-year medical education program consists of 3 consecutive stages. An initial 2.5 years pre-clinical education, commonly known as "basic science" stage, 3 years of clinical training and a final 1.5 years of "internship" which is supervised medical practice at teaching hospitals.

Every year thousands of NUEE candidates, inspired by socio-cultural and economic motives (25-26), compete for medical school admissions. But not all admitted students do well in terms of in-course examination and/or professional behaviors. Though significant changes in the medical school admission processes are beyond reach in the near future $(9,24)$, any intervention to improve students' academic performance should be based on better understanding of determining factors. The present study aims to find determinants of academic success in Iranian medical students during their first 2.5 years of education.

\section{Methods}

Participants

All 200 freshmen of Iran University of Medical Sciences (IUMS) Medical School in 2010, enrolled in the study. IUMS is one of the three highest ranked public medical schools in Iran, located in Tehran.

\section{Instrument}

Data on demographic characteristics and cognitive ability measures of students were collected by uniformly designed, self-administered data collection forms consisting multiple choice and open-ended questions. Demographic characteristics included age, sex, local residence of the family, having a paid job, extracurricular activities (i.e. being professionally involved in sport/ art/social/religious/ political activities).

The cognitive ability measures consisted of the rank in NUEE, Grade Point Averages of High School Graduation Diploma (HSGD-GPA) in 0-20 scale, Grade Point Average of Pre-University Course (PUC-GPA) in 0-20 scale, number of times one had taken part in NUEE, in addition to his/her Biology, Chemistry and Math scores in NUEE (in 0-100 scale).

There are some limited privileges in NUEE. Compared to ordinary candidates, Privileged ones need lower scores to be admitted to any program. Therefore, students were asked about being eligible for any privileges in NUEE.

The students' personality traits were chosen as delegates for their non-cognitive characteristics. An already validated Persian version of NEO Five-Factor (personality) Inventory (NEO-FFI) was used to serve the purpose (27). The NEO-FFI is a 60 -item questionnaire, consisted of 5 domains of Neuroticism (N), Extraversion (E), Openness (O), Agreeableness (A) and Conscientiousness (C). There are 12-items for each domain, and the respondents are asked to rate the extent to which he or she concurs with a statement on a five-point Likert scale, ranging from strongly disagree $(=1)$ to strongly agree $(=5)$. We used the self-report form of inventory which takes 10-15 minutes to be filled. The raw and T-scores in each domain were calculated according to the Persian translation of user manual (28). T scores of 34 and less were interpreted as very low, 35-44 as low, 45-54 as moderate, 55-64 as high, 65 and more as very high scale scores in each domain. By making different combinations of the 5 major personality factors, 10 personality styles are driven including styles of learning $(\mathrm{O}+\mathrm{C})$, character $(\mathrm{A}+\mathrm{C})$, interest $(\mathrm{E}+\mathrm{O})$, attitude $(\mathrm{O}+\mathrm{A})$, interactions $(\mathrm{E}+\mathrm{A})$, activity $(\mathrm{E}+\mathrm{C})$, well-being $(\mathrm{N}+\mathrm{E})$, defense $(\mathrm{N}+\mathrm{O})$, anger control $(\mathrm{N}+\mathrm{A})$ and style of impulse control $(\mathrm{N}+\mathrm{C})$. The respondents' learning styles were categorized in 4 groups of "Good Student" $(\mathrm{O}$ T-Score $\left.=>50, \mathrm{C}_{\mathrm{T} \text {-Score }}=>50\right)$, "Dreamer" $\left(\mathrm{O}_{\mathrm{T} \text {-Score }}=>50, \mathrm{C}_{\mathrm{T}}\right.$ Score $<=50)$, "Reluctant Scholar" ( $\mathrm{O}_{\mathrm{T} \text {-Score }}<=50, \mathrm{C}_{\mathrm{T} \text {-Score }}$ $<=50)$ and "by-the- booker" $\left(\mathrm{O}_{\mathrm{T}-\text { Score }}<=50, \mathrm{C}_{\mathrm{T} \text {-Score }}=>\right.$ 50) (28).

\section{Procedure}

In the $3^{\text {rd }}$ week of the first academic semester, at the beginning of a public health course session, the study purpose and protocol were presented to students by one of the authors. Students were assured that the data provided by them, would only serve research purposes; their participation/ refusal would not influence their academic evaluations and their ID would be kept confidential. Following the instructions, a data gathering form and the NEO FiveFactor (personality) Inventory (NEO-FFI) were handed to each audience. Those willing to participate filled and restored the forms within 20 minutes. Students were followed for 5 consecutive semesters (September 2010- February 2013).

\section{Outcome measures and analysis}

The 5 semesters' cumulative Grade Point Average (GPA), in 0 to 20 scale, was chosen as the main measure of students' academic performance. Traditionally the "A grade" students, those with an overall GPA of 17 or above, are honored as successful students in Iran. So we made further comparisons between "A grade" and "non-A grade" students.

Two independent samples (pooled) t-test and one-way analysis of variance (ANOVA) were used for comparison of means. Since the Kolmogorov-Smirnov test showed that the main dependent variable (i.e. first 2.5 years med school GPA) data was not normally distributed ( $\mathrm{p}>0.05)$, the linear correlation between variables was assessed by Spearman coefficients of correlation, To determine predictors of academic success, Multiple Linear Regression (GPA score as dependent factor HSGD-GPA, PUC-GPA, Biology, Chemistry and Math scores in NUEE, raw and $\mathrm{T}$ scores of NEO-FFI domains as explanatory variables) and Logistic Regression Model (being "A grade" student as dependent factor, and the rest of demographic, cognitive and non-cognitive characteristics as predictors) were used. All analyses were performed by SPSS statistical software (version 16.0, SPSS Inc., Chicago, Ill., USA).

The Research council of Iran University of Medical Sciences approved the study. 
Table 1. Comparison of demographic characteristics in male and female participants $(\mathrm{n}=143)$

\begin{tabular}{|c|c|c|c|c|}
\hline Variable & & Male & Female & P. value \\
\hline \multirow[t]{2}{*}{ Privilege } & No & $47(95.9)^{*}$ & $80(92)$ & 0.6 \\
\hline & yes & $2(4.1)$ & $7(8)$ & \\
\hline \multirow{3}{*}{ Type of high school } & Governmental & $15(27.8)$ & $30(34.1)$ & 0.620 \\
\hline & Nonprofit & $15(27.8)$ & $19(21.6)$ & \\
\hline & Sampad & $24(44.4)$ & $39(44.3)$ & \\
\hline \multirow{2}{*}{ Tehran(or karaj) Native } & Yes & $19(35.8)$ & $41(46.6)$ & 0.2 \\
\hline & No & $34(64.2)$ & $47(53.4)$ & \\
\hline \multirow[t]{3}{*}{ Residence of student } & With family & $27(50)$ & $49(55.1)$ & 0.181 \\
\hline & Dormitory & 21(38.9) & $37(41.5)$ & \\
\hline & Others & $6(11.1)$ & $3(3.3)$ & \\
\hline \multirow{2}{*}{ Paid Job } & Yes & $5(9.3)$ & $7(7.8)$ & 0.77 \\
\hline & No & $49(90.7)$ & $82(92.1)$ & \\
\hline \multirow[t]{2}{*}{ Extracurricular activity } & Yes & $21(38.8)$ & $23(25.8)$ & 0.1 \\
\hline & No & $23(42.5)$ & $66(74.1)$ & \\
\hline
\end{tabular}

\section{Results}

Demographic characteristics of participants

143 medical students were evaluated. Out of $200(72 \%$ responsiveness) participants $89(62.24 \%) \mathrm{w}$ ere males, and $54(37.76 \%)$ were females. The majority of respondents $(93 \%)$ were admitted to med school using no privileges; $17 \%(n=24)$ participated in NUEE more than once. $63(44.4 \%)$ respondents were educated in "Sampad" high schools, which accept talented students and have a district entrance exam for primary school graduate students. About $91 \%(n=131)$ of students were not involved in paid jobs (Table 1).
The cognitive characteristics of participants

The mean (SD) participants' PUC-GPA and HSGD-GPA were 19.14(0.63) and $19.27(0.64)$ respectively. The mean (SD) participants' Biology, Chemistry and Math scores in NUEE were 81.5(8.34), 78.56(10.34) and 57.23 (16.94). On average, respondents ranked 368 (95\% CI: 316-420) among 442000 NUEE applicants.

Mean \pm SD PUC-GPA was higher in females (19.25 \pm 0.57$)$ versus males $(18.94 \pm 0.69),(p=0.01)$. While there was no statistically significant difference between gender groups regarding HSGD- GPA $(p=0.09)$, Biology $(\mathrm{p}=0.45)$, Chemistry $(\mathrm{p}=0.32)$ and Math $(\mathrm{p}=0.23)$ scores in NUEE.

Table 2. The personality characteristics of participants according to NEO-FFI domains, comparison by gender

\begin{tabular}{|c|c|c|c|c|c|}
\hline & Variable & Total & Male & Female & P. value \\
\hline \multirow[t]{6}{*}{ Neuroticism } & "Mean (SD) & 50.08(9.93) & 50.15(9.15) & 50.03(10.43) & 0.93 \\
\hline & Very low & $8(5.6)^{*}$ & $1(1.9)$ & $7(7.9)$ & 0.38 \\
\hline & Low & $40(28)$ & $18(33.3)$ & $22(24.7)$ & \\
\hline & Moderate & $49(34.3)$ & $18(33.3)$ & $31(34.8)$ & \\
\hline & high & $37(25.9)$ & $15(27.8)$ & $22(24.7)$ & \\
\hline & Very high & $9(6.3)$ & $2(3.7)$ & $7(7.9)$ & \\
\hline \multirow[t]{6}{*}{ Extraversion } & Mean (SD) & $49.80(10.14)$ & $48.92(9)$ & $50.33(10.78)$ & 0.32 \\
\hline & Very low & $9(6.3)$ & $4(7.4)$ & $5(5.6)$ & 0.37 \\
\hline & Low & $38(26.6)$ & $13(24.1)$ & $25(28.1)$ & \\
\hline & Moderate & $50(35)$ & $23(42.6)$ & $27(30.3)$ & \\
\hline & high & $36(25.2)$ & $11(20.4)$ & $25(28.1)$ & \\
\hline & Very high & $10(7)$ & $3(5.6)$ & $7(7.9)$ & \\
\hline \multirow[t]{6}{*}{ Openness } & Mean (SD) & $49.72(9.71)$ & $49.97(9.04)$ & $49.58(10.14)$ & 0.77 \\
\hline & Very low & $8(5.6)$ & $2(3.7)$ & $6(6.7)$ & 0.82 \\
\hline & Low & $38(26.6)$ & $15(27.8)$ & $23(25.8)$ & \\
\hline & Moderate & $55(38.5)$ & $20(37)$ & $35(39.3)$ & \\
\hline & high & $29(20.3)$ & $13(24.1)$ & $16(18)$ & \\
\hline & Very high & $13(9.1)$ & $4(7.4)$ & $9(10.1)$ & \\
\hline \multirow[t]{6}{*}{ Agreeableness } & Mean (SD) & $49.80(9.87)$ & $50.66(9.72)$ & $49.27(9.98)$ & 0.31 \\
\hline & Very low & $9(6.3)$ & $2(3.7)$ & $7(7.9)$ & 0.22 \\
\hline & Low & $35(24.5)$ & $14(25.9)$ & $21(23.6)$ & \\
\hline & Moderate & $48(33.6)$ & $17(31.5)$ & $31(34.8)$ & \\
\hline & high & $45(31.5)$ & $18(33.3)$ & $27(30.3)$ & \\
\hline & Very high & $6(4.2)$ & $3(5.6)$ & $3(3.4)$ & \\
\hline \multirow[t]{6}{*}{ Conscientiousness } & Mean (SD) & $50.11(10.09)$ & $48.41(10.10)$ & $51.14(10)$ & 0.055 \\
\hline & Very low & $17(11.9)$ & $6(11.1)$ & $11(12.4)$ & 0.20 \\
\hline & Low & $24(16.8)$ & $10(18.5)$ & $14(15.7)$ & \\
\hline & Moderate & $49(34.3)$ & $24(44.4)$ & $25(28.1)$ & \\
\hline & high & $44(30.8)$ & $11(20.4)$ & $33(37.1)$ & \\
\hline & Very high & $9(6.3)$ & $3(5.6)$ & $6(6.7)$ & \\
\hline
\end{tabular}


Table 3. Comparison of GPA in different group of participants regarding their demographic and non-cognitive characteristics

\begin{tabular}{|c|c|c|c|c|c|}
\hline & Variable & Category & Mean & Standard Deviation & $P$ value \\
\hline \multirow{17}{*}{$\begin{array}{l}\text { Demographic } \\
\text { characteristics }\end{array}$} & \multirow{2}{*}{ Gender } & male & 15.94 & 1.18 & \multirow[t]{2}{*}{0.008} \\
\hline & & Female & 16.51 & 1.26 & \\
\hline & \multirow[t]{2}{*}{ Privilege } & No & 16.47 & 1.14 & \multirow[t]{2}{*}{$<0.0001$} \\
\hline & & yes & 14.93 & 1.38 & \\
\hline & \multirow[t]{2}{*}{ Participation in NUEE } & once & 16.40 & 1.25 & \multirow[t]{2}{*}{0.034} \\
\hline & & More than once & 15.81 & 1.21 & \\
\hline & \multirow[t]{2}{*}{ Tehran native } & yes & 16.05 & 1.16 & \multirow[t]{2}{*}{0.052} \\
\hline & & No & 16.47 & 1.30 & \\
\hline & \multirow{2}{*}{ Residence in dormitory } & yes & 16.48 & 1.35 & \multirow[t]{2}{*}{0.149} \\
\hline & & No & 16.17 & 1.19 & \\
\hline & \multirow[t]{2}{*}{ Paid job } & yes & 15.73 & 0.65 & \multirow[t]{2}{*}{0.011} \\
\hline & & No & 16.35 & 1.29 & \\
\hline & \multirow[t]{2}{*}{ Extracurricular activity } & yes & 16.40 & 0.91 & \multirow[t]{2}{*}{0.45} \\
\hline & & No & 16.25 & 1.39 & \\
\hline & \multirow[t]{3}{*}{ Type of high school } & Governmental & 16.32 & 1.49 & \multirow[t]{3}{*}{0.85} \\
\hline & & Non-profit & 16.45 & 1.13 & \\
\hline & & Sampad & 16.23 & 1.23 & \\
\hline \multirow{29}{*}{$\begin{array}{l}\text { Non-cognitive } \\
\text { characteristics }\end{array}$} & \multirow{5}{*}{ neuroticism } & Very low & 15,46 & 1.04 & \multirow[t]{5}{*}{0.173} \\
\hline & & Low & 16.35 & 1.20 & \\
\hline & & Moderate & 16.17 & 1.34 & \\
\hline & & high & 16.45 & 1.30 & \\
\hline & & Very high & 16.87 & 0.73 & \\
\hline & \multirow[t]{5}{*}{ Extraversion } & Very low & 16.50 & 1.11 & \multirow[t]{5}{*}{0.578} \\
\hline & & Low & 16.10 & 1.37 & \\
\hline & & Moderate & 16.51 & 1.10 & \\
\hline & & high & 16.19 & 1.38 & \\
\hline & & Very high & 16.20 & 1.27 & \\
\hline & \multirow{5}{*}{ Openness } & Very low & 16.26 & 1.77 & 0.471 \\
\hline & & Low & 16.14 & 1.28 & \\
\hline & & Moderate & 16.48 & 1.25 & \\
\hline & & high & 16.38 & 1.11 & \\
\hline & & Very high & 15.83 & 1.24 & \\
\hline & Agreeableness & Very low & 16.62 & 1.39 & 0.840 \\
\hline & & Low & 16.41 & 1.15 & \\
\hline & & Moderate & 16.15 & 1.23 & \\
\hline & & high & 16.29 & 1.32 & \\
\hline & & Very high & 16.30 & 1.72 & \\
\hline & Conscientiousness & Very low & 16.35 & 1.34 & 0.963 \\
\hline & & Low & 16.33 & 1.28 & \\
\hline & & Moderate & 16.19 & 1.16 & \\
\hline & & high & 16.38 & 1.39 & \\
\hline & & Very high & 16.22 & 1.16 & \\
\hline & Learning style & Good student & 16.26 & 1.39 & 0.933 \\
\hline & & Dreamer & 16.40 & 1.19 & \\
\hline & & Reluctant scholar & 16.22 & 1.26 & \\
\hline & & By-the-booker & 16.35 & 1.20 & \\
\hline
\end{tabular}

The non-cognitive characteristics of participants

The mean $\pm \mathrm{SD}$ of respondents' scores in "Neuroticism" and "Extraversion" domains of the NEO-FFI were $50.08 \pm 9.93$ and $49.80 \pm 10.14$ respectively. On average, participants scored $49.72 \pm 9.71$ in "Openness", 49.80 \pm 9.87 in "Agreeableness" and 50.11 10.09 in "Conscientiousness" domains. The personality characteristics of participants according to NEO-FFI T scores are summa- rized in Table 2.

Regarding the learning style, 40 participants (male: female ratio $=11: 29)$ were categorized as "Good students", $26(14: 12)$ as "Dreamers", 39 (17:22) and 38 (12:26) as "Reluctant scholars" and "By-the-bookers" respectively. The differences of learning styles in males and females were not statistically significant $(\mathrm{p}=0.12)$. 


\begin{tabular}{|c|c|c|c|c|c|}
\hline & Variable & Category & $\begin{array}{l}\text { "grade A" students } \\
(\mathrm{n}=41)\end{array}$ & $\begin{array}{l}\text { "non grade A" } \\
\text { Students }(\mathrm{n}=102)\end{array}$ & P. value \\
\hline \multirow{17}{*}{$\begin{array}{l}\text { Demographic } \\
\text { characteristics }\end{array}$} & \multirow[t]{2}{*}{ Gender } & Male & $9(21.9)$ & $45(44.1)$ & \multirow[t]{2}{*}{0.013} \\
\hline & & Female & $32(87.8)$ & $57(55.8)$ & \\
\hline & \multirow[t]{2}{*}{ Privilege } & no & $40(97.5)$ & $87(85.3)$ & \multirow[t]{2}{*}{0.035} \\
\hline & & yes & $1(2.4)$ & $15(14.7)$ & \\
\hline & \multirow{2}{*}{ Participation in NUEE } & Once & $38(92.6)$ & $71(69)$ & \multirow{2}{*}{0.042} \\
\hline & & More than once & $2(4.8)$ & $22(21.5)$ & \\
\hline & \multirow{2}{*}{ Tehran native } & yes & $14(34.1)$ & $46(45)$ & \multirow{2}{*}{0.230} \\
\hline & & no & $27(65.8)$ & $56(54.9)$ & \\
\hline & \multirow[t]{2}{*}{ Residence in Dormitory } & Yes & $21(51.2)$ & $37(36.2)$ & \multirow[t]{2}{*}{0.1} \\
\hline & & No & $20(48)$ & $65(63.7)$ & \\
\hline & \multirow[t]{2}{*}{ Paid job } & Yes & 0 & $12(11.7)$ & \multirow[t]{2}{*}{0.02} \\
\hline & & No & $41(100)$ & $90(88.2)$ & \\
\hline & \multirow[t]{2}{*}{ Extracurricular activity } & Yes & $11(26.8)$ & $33(32.3)$ & \multirow[t]{2}{*}{0.517} \\
\hline & & No & $30(73.1)$ & $69(67.6)$ & \\
\hline & \multirow[t]{3}{*}{ Type of high school } & Governmental & $15(36.5)$ & $30(29.4)$ & \multirow[t]{3}{*}{0.290} \\
\hline & & Non-profit & $12(29.2)$ & $21(20.5)$ & \\
\hline & & Sampad & $14(34.1)$ & $62(60.7)$ & \\
\hline \multirow{29}{*}{$\begin{array}{l}\text { Non-cognitive } \\
\text { characteristics }\end{array}$} & \multirow[t]{5}{*}{ Neuroticism } & Very low & $0(0)$ & $8(7.8)$ & \multirow[t]{5}{*}{0.08} \\
\hline & & Low & $11(26.8)$ & $29(28.4)$ & \\
\hline & & Moderate & $11(26.8)$ & $38(37.3)$ & \\
\hline & & high & $16(39)$ & $21(20.6)$ & \\
\hline & & Very high & $3(7.3)$ & $6(5.9)$ & \\
\hline & \multirow{5}{*}{ Extraversion } & Very low & $3(7.3)$ & $6(5.9)$ & \multirow{5}{*}{0.93} \\
\hline & & Low & $9(22)$ & $29(28.4)$ & \\
\hline & & Moderate & $16(39)$ & $34(33.3)$ & \\
\hline & & high & $10(24.4)$ & $26(25.5)$ & \\
\hline & & Very high & $3(7.3)$ & $7(6.9)$ & \\
\hline & \multirow[t]{5}{*}{ Openness } & Very low & $4(9.8)$ & $4(3.9)$ & 0.475 \\
\hline & & Low & $8(19.5)$ & $30(29.4)$ & \\
\hline & & Moderate & $18(43.9)$ & $37(36.3)$ & \\
\hline & & high & $8(19.5)$ & $21(20.6)$ & \\
\hline & & Very high & $3(7.3)$ & $10(9.8)$ & \\
\hline & Agreeableness & Very low & $3(7.3)$ & $6(5.9)$ & 0.98 \\
\hline & & Low & $9(22)$ & $26(25.5)$ & \\
\hline & & Moderate & $14(34.1)$ & $34(33.3)$ & \\
\hline & & high & $13(31.7)$ & $32(31.4)$ & \\
\hline & & Very high & $2(4.9)$ & $4(3.9)$ & \\
\hline & Conscientiousness & Very low & $6(14.6)$ & $11(10.8)$ & 0.74 \\
\hline & & Low & $8(19.5)$ & $16(15.7)$ & \\
\hline & & Moderate & $11(26.8)$ & $38(37.3)$ & \\
\hline & & high & $14(34.1)$ & $30(29.4)$ & \\
\hline & & Very high & $2(4.9)$ & $7(6.9)$ & \\
\hline & Learning style & Good student & $11(26.8)$ & $29(28.4)$ & 0.79 \\
\hline & & Dreamer & $9(21.9)$ & $17(16.6)$ & \\
\hline & & Reluctant scholar & $12(29.2)$ & $27(26.4)$ & \\
\hline & & By-the-booker & $9(21.9)$ & $29(28.4)$ & \\
\hline
\end{tabular}

The Academic performance of participants

The Mean \pm SD of participants' GPA in their first 2.5 years of med school was $16.30 \pm 1.26$ (min: 12.55, max: $18.78)$ and $41(28.7 \%)$ of them were "grade A" students.

Table 3 compares the GPA in different groups of participants. There was a statistically significant difference in participants' GPA regarding their gender $(\mathrm{p}=0.008)$, using privilege in NUEE $(p<0.0001)$, the number of time one has taken part in NUEE $(\mathrm{p}=0.034)$ and being occupied in paid jobs $(\mathrm{p}=0.01)$. There were linear correlations between first 2.5 years of med school GPA and PUC-GPA ( $\mathrm{r}=0.56$ $\mathrm{p}<0.0001)$, HSGD-GPA $(\mathrm{r}=0.52, \mathrm{p}<0.0001)$, Biology score $(\mathrm{r}=0.32 \mathrm{p}<0.0001)$ and Chemistry score in NUEE. $(\mathrm{r}=0.19, \mathrm{p}=0.032)$. While Math score in NUEE $(\mathrm{r}=0.06$, $\mathrm{p}=0.949)$ and the students' rank in the exam $(\mathrm{r}=-0.15$, $\mathrm{p}=0.154)$ showed no linear correlation with their GPA There were no statistically significant differences in participants' GPA regarding NEO-FFI domains. Neither raw nor T scores of NEO-FFI domains had linear correlations with GPA. There was no difference in GPA of students regarding their learning style.

Table 4, shows the distribution of different Demographic and non-cognitive characteristics in "grade A" and "nongrade A" students. Gender ( $p=0.01)$, privilege in admission to university $(\mathrm{p}=0.03)$, frequency of participation in NUEE $(p=0.04)$, being occupied in paid jobs $(p=0.02)$ significantly differed in two groups. The Biology score in NUEE was significantly different in "grade A" and "nongrade A" students ( $\mathrm{p}=0.006)$; while there were no differences between groups regarding Chemistry $(p=0.093)$ and 
Math $(\mathrm{p}=0.88)$ scores as well as NUEE rank $(\mathrm{p}=0.123)$.

The Multiple Linear Regression model did not explain variations of students' GPA by variations in HSGD-GPA, PUC-GPA, Biology, Chemistry and Math scores in NUEE, raw and T scores of NEO-FFI domains. A logistic regression model also revealed none of the demographic, cognitive and non-cognitive characteristics as "predictors" of being an "A grade" student in the first 2.5 years of Medical school.

\section{Discussion}

Academic performance and Demographic characteristics

Female participants academically performed better than males. The same finding was reported in single studies from Sri Lanka, Germany, Turkey, Scotland and Saudi Arabia (1,3-4,6-8, 29). The systematic review by Ferguson et al. also concluded that "women tend to perform better than men in their medical training." They suggested "motivation" as the probable explanation for the phenomenon (5).

It has been suggested that extracurricular activities have a negative effect on students' academic performance (3). While we found no differences in academic performance of students regarding their professional involvement in extracurricular activities, it was revealed that those who were occupied in paid jobs, performed less successful compared to others.

\section{Academic performance and cognitive characteristics}

It has consistently been stated in the literature that the academic performance of students prior to their admission to the medical school is a strong predictor of their medical school academic success $(2,5-7,12,14-16,30)$. The same finding was repeated in the current study. Matriculants who passed the NUEE in the first and only time they took the exam, and those who used no privileges in NUEE had better academic results in medical school. The linear correlations between med school GPA and PUC-GPA, HSGD-GPA, Biology and Math points in the NUEE also indicate that medical students' academic performance is correlated to their academic performance prior to med school admission.

The volunteers' Rank in NUEE did not predict the medical school academic performance. A cohort done by Farrokhi-Khajeh-Pasha et al. on all public medical schools in Iran also reported the same finding (30). This might probably be due to the small number of variations between students' scores in the highly competitive NUEE.

\section{Academic performance and mon-cognitive characteris- tics}

While many studies have emphasized on the role of personality characteristics $(1,16-17,19-21,23-24,31-34)$, particularly the conscientiousness $(5-6,23,33-34)$ in medical students' academic success, the present study failed to prove such correlations. The fact that we followed the participants just through their "basic science" stage might be an explanation. It has already been shown that during the early pre-clinical years, where success is mostly defined in terms of in-course examination scores, personality traits play a less important role. As the curriculum changes over the years, the personality, especially interpersonal aspects of it, become more important $(21,33)$. Another explanation is a lack of heterogeneity amongst participants, which leads to a small number of students in some personality subgroups, not sufficient to show any statistical difference.

We were not able to determine any particular variable as the "predictor" of academic success by applying regression models. Females were the majority of participants. They had better academic performance both before (i.e. higher PUC-GPA) and after admission to medical school. So the gender variable might have adjusted the role of other variables when entered in the model.

\section{Limitations and Strengths}

In spite of some generalizability limitations and failing to fit any regression models, the study has its strengths in choosing its measures. Choosing the results of centralized, governmentally administered examinations as indicators of cognitive ability, minimizes the potential bias of using different cognitive ability measurement tools. Applying the validated Farsi version of NEO-FFI inventory provides a better opportunity for comparison of our findings with other studies, since the scale is frequently used as personality assessment tool in the relevant literature.

\section{Conclusion}

In conclusion, gender, privilege in university admission and frequency of participation in NUEE were significantly associated with a better academic performance of medical students after 2.5 years of education. Other demographic and non-cognitive measures seem to have a limited role at this stage. The next phase of this study, which evaluates the same participants through their rest of medical education, may provide a better understanding about predictors of academic performance and professional behavior in Iranian medical students.

\section{Acknowledgment}

This study was conducted with the financial support of IUMS vice chancellor of research (contract number 1023). We would also like to thank all medical students who participated in the study and hope our findings help to develop the better educational programs for them.

Conflict of Interests: The authors declare that they have no competing interests.

\section{References}

1. Lumsden MA, Bore M, Millar K, Jack R, Powis D. Assessment of personal qualities in relation to admission to medical school. Med Educ. 2005 Mar;39(3):258-65.

2. Salvatori P. Reliability and validity of admissions tools used to select students for the health professions. Adv Health Sci Educ Theory Pract. 2001;6(2):159-75.

3. de Silva NR, Pathmeswaran A, de Silva HJ. Selection of students for admission to a medical school in Sri Lanka. Ceylon Med J. 2004;49:815.

4. de Silva NR, Pathmeswaran A, de Silva N, Edirisinghe JS, Kumarasiri PV, Parameswaran SV, et al. Admission to medical schools in Sri 
Lanka: predictive validity of selection criteria. Ceylon Med J. 2006 51(1):17-21.

5. Ferguson E, James D, Madeley L. Factor $\mathrm{s}$ associated with success in medical school: systematic review of the literature. BMJ. 2002;324:952-7.

6. Haidinger G, Frischenschlager $O$, L. M. Prediction of success in the first-year exam in the study of medicine--a prospective survey. . Wien Klin Wochenschr. 2005;117(23-24):827-32.

7. Haidinger G, Frischenschlager $O$, L. M. Reliability of predictors of study success in medicine. Wien Med Wochenschr. 2006;156(1314):416-20.

8. Salem RO, Al-Mously N, Nabil NM, Al-Zalabani AH, Al-Dhawi AF, AlHamdan N. Academic and socio-demographic factors influencing students' performance in a new Saudi medical school. Med Teach. 2013;35 Suppl 1:S83-9.

9. Kim KJ, Kee C. Gifted students' academic performance in medical school: a study of Olympiad winners. Teach Learn Med. 2012;24(2):128-32.

10. Adam J, Bore M, McKendree J, Munro D, Powis D. Can personal qualities of medical students predict in-course examination success and professional behaviour? An exploratory prospective cohort study. BMC Med Educ. 2012;12:69.

11. Donnon T, Paolucci EO, C. i. The predictive validity of the MCAT for medical school performance and medical board licensing examinations: a meta-analysis of the published research. Acad Med. 2007;82:100 - 6 .

12. Bastias G, Villarroel L, Zuniga D, Marshall G, Velasco N, B M. Academic performance of medical students: a predictable result? Rev Med Chil. 2000;128:671-8.

13. Hoschl C, Kozeny J. Predicting academic performance of medical students: the first three years. Am J Psychiatry. 1997;154:87-92.

14. James D, Chilvers C. Academic and non-academic predictors of success on the Nottingham undergraduate medical course 1970-1995. Med Educ. 2001;35(11):1056-64.

15. Lumb AB, A. V. Comparison of academic, application form and social factors in predicting early performance on the medical course. Med Educ. 2004;38:1002-5.

16. McCall KL, Allen DD, Fike DS. Predictors of academic success in a doctor of pharmacy program. Am J Pharm Educ. 2006;70(106).

17. O'Connor MC, Paunonen SV. Big Five personali ty predictors of postsecondary academic performance. Personality and Individual Differences 2007;43:971-90.

18. Shen H CA. Factorial validity of personality structure in medical school applicants. Educ Psychol Meas. 1995;55:1008-15.

19. Lievens F, Coetsier P, De Fruyt F, De Maeseneer I. Medical students' personality characteristics and academic performance: a five-factor model perspective. Medical Education. 2002;36:1050-6.

20. Poropat AE. A Meta-Analysis of the Five-Factor Model of Personality and Academic Performance Psychol Bull 2009 135(2):322-38.

21. Doherty EM, Nugent E. Personality factors and medical training: a review of the literature. Med Educ. 2011 Feb;45(2):132-40.

22. Parlow J, Al. R. Personality traits of first year medical students: Trends over a six-year period 1967-72. Br J Med Educ. 1974;8:8-12.

23. Ferguson E, James D, O'Hehir F, Sanders A, IC M. Pilot study of the roles of personality, references, and personal statements in relation to performance over the five years of a medical degree. BMJ. 2003;326:429-32.

24. Benbassat J, Baumal R. Uncertainties in the selection of applicants for medical school. Adv Health Sci Educ Theory Pract. 2007 Nov;12(4):509-21.

25. Nedjat S, Majdzadeh R, A R. Graduate entry to medicine in Iran. BMC Med Educ. 2008;8:47.

26. Kamyab. The university entrance exam crisis in Iran. IJHE. 2008;51:22-3.

27. Fathi Ashtiani, A., cognitive tests, personality and mental health assessment. 1 ed. 2009, Tehran: Besat (Persian).

28. Haghshenas, H., Five-Factor personality Model 1997, Shiraz: Shiraz Medical University Press.

29. Dayıoglu M, Türüt-Asık S. Gender Differences in Academic Performance in a Large Public University in Turkey Ankara. Ankara: Middle
East Technical University; 2004

30. Farrokhi-Khajeh-Pasha y, Nedjat Sh, Mohammadi A, Rad EM, Majdzadeh R, Monajemi F, et al. The validity of Iran's national university entrance examination (Konkoor) for predicting medical students' academic performance. BMC Medical Education. 2012,;12(60):12:60.

31. Kulatunga-Moruzi C, GR. N. Validity of admissions measures in predicting performance outcomes: the contribution of cognitive and noncognitive dimensions. Teach Learn Med. 2002;14:34-42.

32. Powis D. Selecting medical students. Med J aust. 2008;188:323-4.

33. Lievens F, Ones DS, Dilchert S. Personality scale validities increase throughout medical school. J Appl Psychol. 2009 Nov;94(6):1514-35.

34. Noftle EE, Robins RW. Personality predictors of academic outcomes: big five correlates of GPA and SAT scores. J Pers Soc Psychol. 2007 Jul;93(1):116-30. 